\title{
Enhanced Gases Separation of Cellulose Acetate Membrane Using N-Methyl-1-2 Pyrrolidone as Fabrication Solvent
}

\author{
M. Mubashir, Y. Y. Fong*, C. T. Leng and L. K. Keong \\ Universiti Teknologi PETRONAS \\ *Email: yinfong.yeong@utp.edu.my \\ Phone: +6053687564; Fax: +6053656176
}

\begin{abstract}
Among the various polyimides, cellulose acetate (CA) as the membrane material in the market of gases separation processes is extensively used. However, CA membrane demonstrates relatively low $\mathrm{CO}_{2}$ permeability and low $\mathrm{CO}_{2} / \mathrm{N}_{2}$ and $\mathrm{CO}_{2} / \mathrm{CH}_{4}$ gas pair selectivity. Besides, fabrication of defect-free CA membrane challenging, and fabrication solvent control the non-selective voids of the membrane. Although, there were few studies reported on the development of CA membrane using various solvents; the fabrication of CA membrane using methyl-2-pyrrolidone (NMP) is scarcely reported in the literature and detailed investigation is needed. Thus, the objective of the present work is to fabricate CA membrane using NMP solvent. Analytical tools have verified the structure, morphology and bond vibration of the resultant membrane, respectively. The resultant CA membrane showed the $\mathrm{CO}_{2}$ permeability, $\mathrm{CO}_{2} / \mathrm{CH}_{4}$ and $\mathrm{CO}_{2} / \mathrm{N}_{2}$ ideal selectivity of 15.56 Barrer, 10.71 and 8.80, respectively. The performance of the resultant membrane was found higher the previously reported studies for CA membrane fabricated using different solvents. Thus, it can be concluded that the NMP is effective solvent and it can be recommended to use a solvent for fabrication of other types of membranes.
\end{abstract}

Keywords: Cellulose acetate (CA), membrane, fabrication, gases separation, N-Methyl2-pyrrolidone (NMP).

\section{INTRODUCTION}

The rise of $\mathrm{CO}_{2}$ concentration in the atmosphere is the main culprit for the climate change and global warming [1]. $\mathrm{CO}_{2}$ separation using membrane process is highly attractive compared to other conventional separation technologies because of their features including low cost, ease of maintenance, smaller footprint, and low labor intensity [1-7]. These benefits endow the membrane as a significant and competitive technology for $\mathrm{CO}_{2}$ separation [8,9]. Therefore, fabrication of membranes in gases separation is increasing tremendously. Typically, inorganic membranes possess a number of limitations including, high fabrication cost and complex fabrication procedure $[8,9]$. On the other hand, mixed matrix membranes (MMMs) still facing severe challenging tasks including, poor compatibility between inorganic filler with the polymer matrix and particles agglomeration [10, 11]. The successful application of polymeric membranes in the $\mathrm{CO}_{2} / \mathrm{N}_{2}$ and $\mathrm{CO}_{2} / \mathrm{CH}_{4}$ separation is mainly due to economical processing capabilities and high mechanical stability [3, 12]. Polymers include cellulose acetate (CA), polysulfones (PSF), polyimides (PI), silicone rubber, 
polyphenylene oxide are commonly used for $\mathrm{CO}_{2} / \mathrm{N}_{2}$ and $\mathrm{CO}_{2} / \mathrm{CH}_{4}$ separation [13]. On the basis of materials, there are two types of polymeric membranes which include; glassy and rubbery polymers. From the literature, it has been found that the glassy polymers demonstrated higher perm-selectivity and higher chemical resistance compared to rubbery polymers [14]. Furthermore, among the glassy polymers, polyimides demonstrated better performance in $\mathrm{CO}_{2} / \mathrm{CH}_{4}$ separation.

Among the various polyimides, inclusive use of CA material in the market of gases separation processes is mostly because of to its low manufacturing cost, good toughness, and virtuous compatibility. In addition, CA polymer demonstrated good fouling resistance, ease of processability and high $\mathrm{CO}_{2}$ solubility $[15,16]$. Thus, various researchers reported on the fabrication of CA membrane for gases separation [15-18]. Recently, acetone has been used by the Carine et al. [17] as a solvent for fabrication of $\mathrm{CA}$ membrane. They found that $\mathrm{CO}_{2}$ permeability of 6.1 Berrer and $\mathrm{CO}_{2} / \mathrm{CH}_{4}$ selectivity of 5.08 were achieved. Consequently, Seng et al. [18] reported the performance of CA membrane fabricated using THF solvent. $\mathrm{CO}_{2}$ and $\mathrm{N}_{2}$ permeability of 4.55 and 1.0 Barrer were obtained, respectively. Meanwhile, the $\mathrm{CO}_{2} / \mathrm{N}_{2}$ selectivity of 4.55 was achieved.

On the other hand, as reported in the literature, the fabrication of polymeric membranes using NMP solvent usually resulted in the polymeric membrane with improved fractional free volume and thus, enhanced the gases permeation performance [19]. In 2011, Sikander and his coworkers [20] studied the NMP/DCM composition effect on the permeation performance of PSF membrane for $\mathrm{CO}_{2}$ removal from $\mathrm{CH}_{4}$. They observed that the $\mathrm{CO}_{2}$ permeability was increased with the increase of NMP concentration in the NMP/DCM solution and thus, $\mathrm{CO}_{2} / \mathrm{CH}_{4}$ gas pair selectivity was increased from 19 to 26. Recently, Chung et al. [21] reported the fabrication of 6FDAdurene membrane using NMP solvent. They obtained a $\mathrm{CO}_{2} / \mathrm{CH}_{4}$ selectivity of 16.59 which was $137 \%$ higher compared to the selectivity reported for 6FDA-durene membrane fabricated using DCM solvent [22]. These results are mainly because of NMP solvent which enhances the hydrogen bonding between $\mathrm{OH}^{-}$groups of polymers. Thus, non-selective voids reduced and the gases selectivities increases. In addition, longer evaporation time of NMP solvent during membrane fabrication also contributed to the enhancement of the $\mathrm{CO}_{2}$ permeability. With longer evaporation duration, polymer chains tend to rigidified and thus, enhanced the penetration of gases through the resultant membrane [19].

Among the various reported CA membrane; the fabrication of CA membrane using NMP is yet to be investigated. Therefore, in the current study, we had reported the fabrication of CA membrane using NMP solvent. Subsequently, the structure, morphology and bond vibration of the resultant CA membrane is investigated by using XRD and FESEM, respectively. Lastly, the permeation performance of resultant CA membrane in $\mathrm{CO}_{2} / \mathrm{CH}_{4}$ and $\mathrm{CO}_{2} / \mathrm{N}_{2}$ separation is evaluated.

\section{EXPERIMENTAL METHOD}

\section{Materials}

Cellulose acetate (CA) was purchased from Sigma Aldrich (Malaysia). N-methylpyrrolidone was purchased from Merck (Malaysia). Polymer and solvent were used as 
received. Table 1 shows the physicochemical properties of the CA polymer and NMP solvent used in the present study.

Table 1: Physicochemical properties of CA polymer and NMP solvent used in the present study $[21,22]$.

\begin{tabular}{lcc}
\hline Physicochemical properties & CA & NMP \\
\hline Density $\left(\mathrm{g} / \mathrm{cm}^{3}\right)$ & 1.30 & 1.03 \\
Boiling point $\left({ }^{\circ} \mathrm{C}\right)$ & NA & 204 \\
Appearance & White powder & Colorless liquid \\
Solubility & Organic compounds & $\begin{array}{c}\text { Organic/inorganic } \\
\text { compounds }\end{array}$ \\
\hline
\end{tabular}

\section{Fabrication of CA Membrane}

In the current work, solution casting method was adopted in order to fabricated pristine CA membrane as described in the literature [23]. CA was mixed into NMP solvent in order to CA/NMP solution. Then, CA/NMP solution was stirred for $18 \mathrm{~h}$ and the concentration of CA was maintained at $10 \mathrm{wt} \%$ in the solution. Then, CA solution was degassed for $12 \mathrm{~h}$. After that, CA solution was cast on Petri dish and it was preceded for drying in an oven at $90{ }^{\circ} \mathrm{C}$ for $24 \mathrm{~h}$. In the next step, the resultant membrane was subjected to the annealing. Annealing of the membrane was conducted under the vacuum condition at $90^{\circ} \mathrm{C}$ for $24 \mathrm{~h}$ with a heating rate of $10^{\circ} \mathrm{C} / 12 \mathrm{~h}$.

\section{Characterization of CA Membrane}

In the current work, XRD (PANayltical) was used to determine the structure of the resultant membrane. XRD was operated at 2 theta range from $5^{\circ} \geq 2 \theta \geq 45^{\circ}$. Subsequently, surface morphology, cross-sectional view, and thickness of the membrane were measured using FESEM (Zeiss Supra 55 VP). Firstly, the membrane was placed into the FESEM chamber and it was operated at $5 \mathrm{kV}$ under vacuum condition. Subsequently, the presence of functional groups and chemical bonds in CA membrane were determined by using ATR-FTIR (Perkin-Elmer Spectrum one). The resultant membrane was scanned for wavenumbers ranging from $400 \mathrm{~cm}^{-1}$ to $4000 \mathrm{~cm}^{-1}$ under the continuously purged $\mathrm{N}_{2}$.

\section{Gases Permeation Measurement}

The permeation performance of the resultant $\mathrm{CA}$ membrane was evaluated by determining the $\mathrm{CO}_{2}, \mathrm{~N}_{2}$, and $\mathrm{CH}_{4}$ permeability as well as $\mathrm{CO}_{2} / \mathrm{N}_{2}$ and $\mathrm{CO}_{2} / \mathrm{CH}_{4}$ gas pair selectivities. The design of the permeation test rig has been reported in our previous proceeding [24]. CA membrane was installed in the permeation cell and it was preceded to vacuum for $12 \mathrm{~h}$ in order to remove the moisture. In the next step, feed gases were injected to the equipment and their pressure was maintained at 3 bar. Subsequently, feed flow rate of gases was $200 \mathrm{~mL} / \mathrm{min}$. The data was produced with an error of $\pm 3 \%$. The gases permeability of the membrane was determined by using Eq. (1) [25]:

$$
\frac{P_{C O_{2}}}{L}=\frac{Q}{A \Delta P}
$$


Where the $\mathrm{CO}_{2}$ permeability of the CA membrane has been presented as $\mathrm{P}_{\mathrm{CO} 2}$ with units of Barrer. Meanwhile, gases flow rates and their pressure drop are shown using the symbol of $Q$ and $\Delta P$, respectively. Subsequently, $\mathrm{CO}_{2}$ and $\mathrm{CH}_{4}$ permeabilities of the membrane were divided in order to calculate the $\mathrm{CO}_{2} / \mathrm{CH}_{4}$ ideal selectivity of the $\mathrm{CA}$ membrane as in Eq. (2) [25]:

$$
\alpha_{\mathrm{CO}_{2} / \mathrm{CH}_{4}}=\frac{P_{\mathrm{CO}_{2}}}{P_{\mathrm{CH}_{4}}}
$$

\section{RESULTS AND DISCUSSION}

\section{X-ray Diffraction (XRD)}

XRD pattern of the resultant CA membrane is presented in Figure 1. Referring to Figure 1 , it has been found that resultant membrane possesses the amorphous structure because no substantial peak is obtained in their XRD pattern. This result was mainly because of non-crystalline nature of the CA polymer. Subsequently, similar, XRD pattern has been reported by the Sanaeepur et al. [16] for CA membrane.

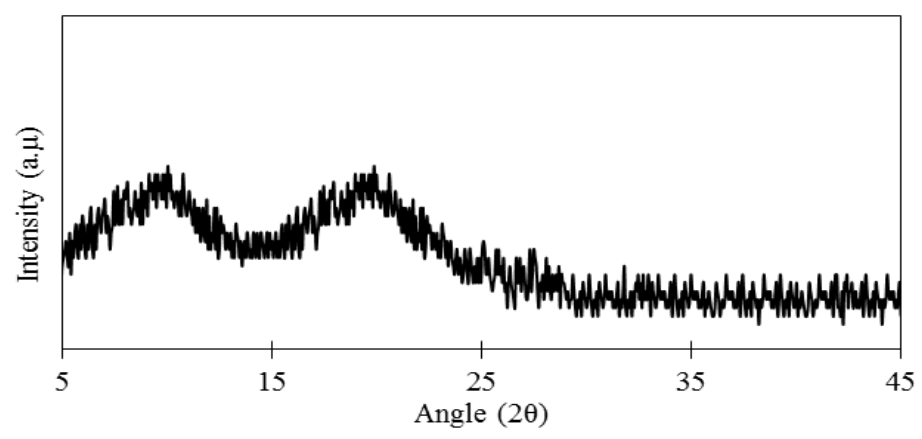

Figure 1. XRD pattern of resultant CA membrane.

\section{Field Emission Scanning Electron Microscopy (FESEM)}

Surface and cross-sectional view of the CA membrane are shown in Figure 2. Referring Figure 2 (a), resultant membrane shows uniform and smooth surface morphology. Referring to Figure 2 (a), the inner structure of the membrane is also homogeneous [26]. Subsequently, it has also been found that there were no obvious voids formed in the resultant membrane. This result could be due to the bonding between $\mathrm{OH}^{-}$-vibrations of the hydroxyl group of CA polymer. Hydrogen bond has been produced by the effect of NMP. Besides, longer evaporation time of NMP also contributes to the slow settling of the polymer and thus it restricted the neighboring $\mathrm{C}-\mathrm{OH}$ rings. Thus, no micro-voids are produced in the membrane [19].

\section{Fourier transform infrared (ATR-FTIR)}

ATR-FTIR analysis of the resultant CA membrane is shown in Figure 3. From Figure 3, it has been found that the resultant membrane showed the characteristics peaks at 660 $\mathrm{cm}^{-1}, 900 \mathrm{~cm}^{-1}, 1032 \mathrm{~cm}^{-1}, 1121 \mathrm{~cm}^{-1}, 1215 \mathrm{~cm}^{-1}, 1367 \mathrm{~cm}^{-1}, 1431 \mathrm{~cm}^{-1}, 1737 \mathrm{~cm}^{-1}$ and $3475 \mathrm{~cm}^{-1}$ [18]. The characteristic peak at $660 \mathrm{~cm}^{-1}$ is due to the aromatic $\mathrm{C}-\mathrm{OH}$ bond 
polymer chain. However, the peak at $900 \mathrm{~cm}^{-1}$ endorses the $\beta$ link [16]. Meanwhile, the broad peaks at $1032 \mathrm{~cm}^{-1}$ and $1121 \mathrm{~cm}^{-1}$ are corresponding to the skeletal movement of C-O bond. Subsequently, significant peaks at $1215 \mathrm{~cm}^{-1}, 1367 \mathrm{~cm}^{-1}, 1431 \mathrm{~cm}^{-1}$ and 1737 $\mathrm{cm}^{-1}$ are mainly due to the $\mathrm{C}-\mathrm{C}-\mathrm{O}$ bonds, $\mathrm{CH}_{3}$ symmetric vibration and $\mathrm{C}=\mathrm{O}$ stretching, respectively [27]. Moreover, peak at $3475 \mathrm{~cm}^{-1}$ endorses $\mathrm{OH}-$ bond of the of CA membrane [27, 28].

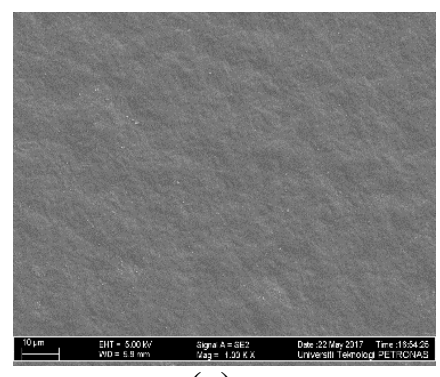

(a)

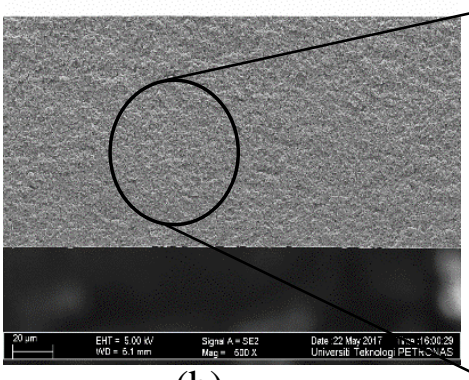

(b)

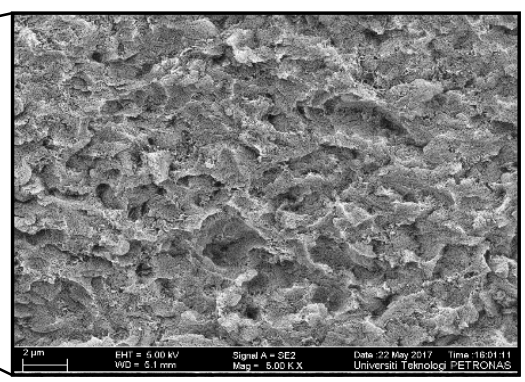

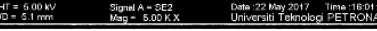

Figure 2. FESEM images of (a) surface and (b) cross-sectional view of CA membrane.

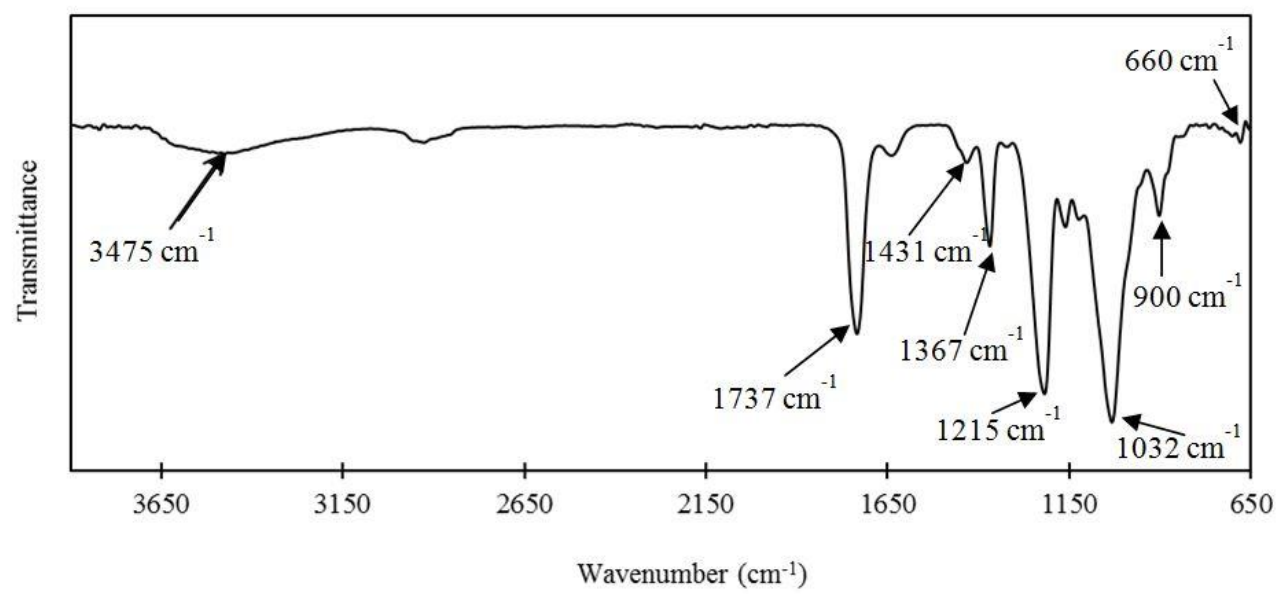

Figure 3. ATR-FTIR analysis of resultant CA membrane.

\section{Gas Permeation Study and Comparison with The Literature Results}

Figure 4 shows the permeation performance of resultant CA membrane. Referring to Figure 4, it has been found that $\mathrm{CO}_{2}$ permeability is higher than that of those values obtained for $\mathrm{N}_{2}$ and $\mathrm{CH}_{4}$ gases. Furthermore, gases permeabilities are decreasing in the order of $\mathrm{CO}_{2}>\mathrm{N}_{2}>\mathrm{CH}_{4}$. This decreasing trend is could be due to the solubility difference of gases in the CA matrix [15]. From Figure 4, it can also be seen that the gas pair selectivities of 10.71 and 8.80 are obtained for the resultant CA membrane, respectively. It is interesting to note that, the gas pair ideal selectivities are also decreasing in the order of $\mathrm{CO}_{2} / \mathrm{CH}_{4}>\mathrm{CO}_{2} / \mathrm{N}_{2}$. This result is attributed to the lower $\mathrm{CH}_{4}$ Langmuir sorption of $\mathrm{CH}_{4}$ compared to the $\mathrm{N}_{2}$ [17]. Therefore, $\mathrm{CH}_{4}$ permeability is smaller than $\mathrm{N}_{2}$ permeability over the resultant $\mathrm{CA}$ membrane. Hence, $\mathrm{CO}_{2} / \mathrm{CH}_{4}$ gas pair ideal selectivity is higher than that of $\mathrm{CO}_{2} / \mathrm{N}_{2}$ gas pair ideal selectivity over the $\mathrm{CA}$ membrane. 


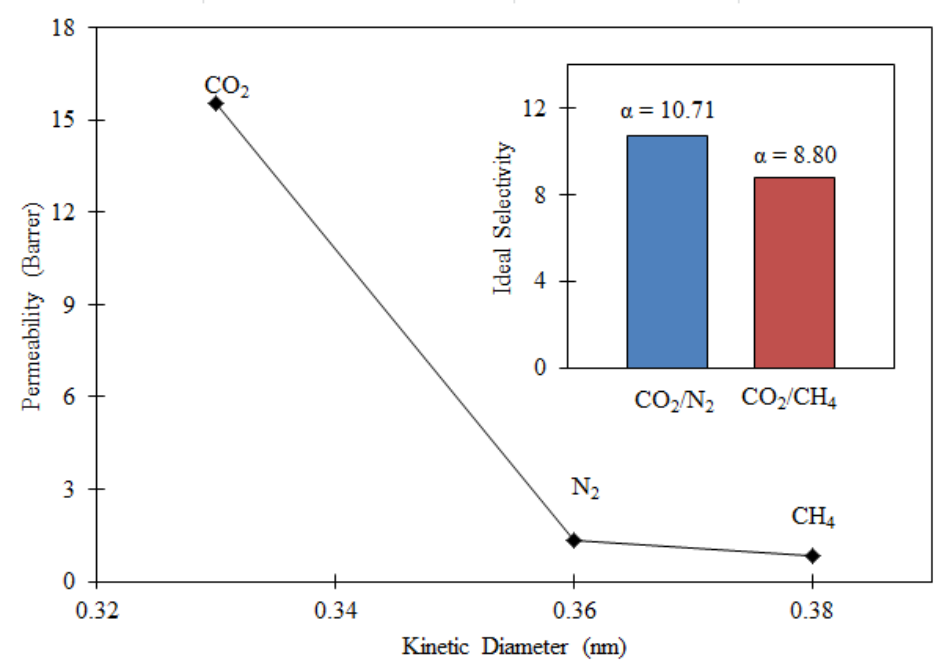

Figure 4: Permeation performance of resultant CA membrane.

Meanwhile, Table 2 shows the comparison of $\mathrm{CO}_{2} / \mathrm{N}_{2}$ and $\mathrm{CO}_{2} / \mathrm{CH}_{4}$ ideal selectivities of CA membrane fabricated in the current study with the reported literature. Referring to Table 2, it has been found that the permeation performance of the resultant CA membrane was higher than those values achieved for CA membrane fabricated using THF and acetone solvents [15, 18, 29]. This result could be because of NMP solvent which enhanced the hydrogen bonding between $\mathrm{OH}^{-}$vibrations of the hydroxyl group and restriction of neighboring $\mathrm{C}-\mathrm{OH}$ rings and thus, increased the rigidity of the polymer chain as well as the gas permeation performance. Besides, longer evaporation time of NMP solvent during membrane fabrication also contributed to the enhancement of $\mathrm{CO}_{2}$ permeability. With longer evaporation duration, polymer chains tend to rigidified with higher free volume and it contributes to enhance the diffusion of gases through the resultant $\mathrm{CA}$ membrane [19]. In the present work, $\mathrm{CO}_{2}$ permeability and gas pair ideal selectivities of the CA membrane were increased about $158 \%$ and $42.3 \%$, respectively compared to the reported literature [15]. Overall, the gas permeation performance has been enhanced using CA membrane fabricated via NMP solvent.

Table 2: Comparison of $\mathrm{CO}_{2} / \mathrm{CH}_{4}$ and $\mathrm{CO}_{2} / \mathrm{N}_{2}$ ideal selectivities of CA membrane fabricated in the present work with reported literature.

\begin{tabular}{|c|c|c|c|c|c|c|}
\hline $\begin{array}{c}\mathrm{CO}_{2} \\
\text { permeability } \\
(\text { Barrer })\end{array}$ & $\begin{array}{c}\mathrm{N}_{2} \\
\text { permeability } \\
(\text { Barrer })\end{array}$ & $\begin{array}{c}\mathrm{CH}_{4} \\
\text { permeability } \\
\text { (Barrer) }\end{array}$ & $\begin{array}{c}\mathrm{CO}_{2} / \mathrm{CH}_{4} \\
\text { selectivity }\end{array}$ & $\begin{array}{c}\mathrm{CO}_{2} / \mathrm{N}_{2} \\
\text { selectivity }\end{array}$ & Solvent & Ref. \\
\hline $15.56 \pm 1$ & $1.77 \pm 0.5$ & $1.45 \pm 0.5$ & $\begin{array}{c}10.71 \pm \\
0.5\end{array}$ & $8.80 \pm 0.5$ & NMP & $\begin{array}{l}\text { This } \\
\text { work }\end{array}$ \\
\hline 1.08 & 0.44 & 0.26 & 4.15 & 2.45 & THF & [15] \\
\hline 6.10 & - & - & 5.08 & - & Acetone & [17] \\
\hline 4.55 & 1.00 & - & - & 4.55 & THF & [18] \\
\hline 0.17 & 0.12 & 0.18 & 0.94 & 1.44 & THF/EtOH & [29] \\
\hline
\end{tabular}




\section{CONCLUSION}

In this work, CA membrane has been fabricated using NMP solvent and its structural properties have been verified using analytical tools. Subsequently, $\mathrm{CO}_{2}$ permeability, $\mathrm{CO}_{2} / \mathrm{CH}_{4}$ and $\mathrm{CO}_{2} / \mathrm{N}_{2}$ ideal selectivities of 15.56 Barrer, 10.71 and 8.80 were achieved, respectively. Consequently, permeation performance of the resultant $\mathrm{CA}$ membrane was higher than those values achieved for previously fabricated CA membrane. Higher permeation performance of resultant CA membrane could be because of NMP solvent which enhanced the hydrogen bonding between $\mathrm{OH}^{-}$vibrations of the hydroxyl group and restriction of neighboring $\mathrm{C}-\mathrm{OH}$ rings and thus, increased the rigidity of the polymer chain as well as the gas permeation performance. Therefore, $\mathrm{CO}_{2}$ permeability and selectivities of resultant CA membrane were increased about $158 \%$ and $42.3 \%$, respectively compared to the reported literature. Overall, the gas permeation performance has been enhanced using CA membrane fabricated via NMP solvent. Therefore, CA membrane fabricated in the current work has a potential for industrial gas separation.

\section{ACKNOWLEDGEMENT}

Authors duly acknowledge the $\mathrm{CO}_{2}$ Research Centre (CO2RES), Institute of Contaminant Management, Universiti Teknologi PETRONAS for the technical and financial support.

\section{REFERENCES}

[1] Mubashir M, Yeong YF, Keong LK, bin Mohd Shariff A. Methods comparison for the synthesis of Deca-dodecasil 3 Rhombohedral (DDR3) zeolite crystals. Applied mechanics and materials: Trans Tech Publ; 2015; 1096-1100.

[2] Xi Y-H, Liu Z, Ji J, Wang Y, Faraj Y, Zhu Y, et al. Graphene-based membranes with uniform 2D nanochannels for precise sieving of mono-/multi-valent metal ions. Journal of Membrane Science. 2018;550:208-18.

[3] Muhammad Mubashir YYF, Lau Kok Keong, Chew Thiam Leng, Norwahyu Jusoh. Efficient $\mathrm{CO} 2 / \mathrm{N} 2$ and $\mathrm{CO} 2 / \mathrm{CH} 4$ Separation by using NH2-MIL53(Al)/Cellulose Acetate (CA) Mixed Matrix Membranes. Separation \& Purification Technology. 2018;199:140-51.

[4] Scott K. Handbook of industrial membranes: Elsevier; 1995.

[5] Lin H, He Z, Sun Z, Kniep J, Ng A, Baker RW, et al. CO2-selective membranes for hydrogen production and $\mathrm{CO} 2$ capture - Part II: Techno-economic analysis. Journal of Membrane Science. 2015;493:794-806.

[6] White LS, Wei X, Pande S, Wu T, Merkel TC. Extended flue gas trials with a membrane-based pilot plant at a one-ton-per-day carbon capture rate. Journal of Membrane Science. 2015;496:48-57.

[7] Muhammad M, Yeong YF, Lau KK, Mohd Shariff AB. Issues and Challenges in the Development of Deca-Dodecasil 3 Rhombohedral Membrane in CO2 Capture from Natural Gas. Separation \& Purification Reviews. 2015;44:331-40.

[8] Ismail AF, Rana D, Matsuura T, Foley HC. Carbon-based membranes for separation processes: Springer Science \& Business Media; 2011. 
[9] Mubashir M, Fong YY, Keong LK, Sharrif MAB. Synthesis and performance of deca-dodecasil 3 rhombohedral (ddr)-type zeolite membrane in $\mathrm{CO} 2$ separationa review. ASEAN Journal of Chemical Engineering (AJChE). 2015;14.

[10] Nasir R, Mukhtar H, Man Z, Mohshim DF. Material Advancements in Fabrication of Mixed-Matrix Membranes. Chemical Engineering \& Technology. 2013;36:717-27.

[11] Muhammad Mubashir YYF, Chew Thiam Leng and Lau Kok Keong. Issues and Current Trend of Hollow Fiber Mixed Matrix Membranes for CO2 Separation from N2 and CH4. Chemical Engineering \& Technology. 2018.

[12] Goh PS, Ismail AF, Sanip SM, Ng BC, Aziz M. Recent advances of inorganic fillers in mixed matrix membrane for gas separation. Separation and Purification Technology. 2011;81:243-64.

[13] Adatoz E, Avci AK, Keskin S. Opportunities and challenges of MOF-based membranes in gas separations. Separation and Purification Technology. 2015;152:207-37.

[14] Chen XY, Vinh-Thang H, Ramirez AA, Rodrigue D, Kaliaguine S. Membrane gas separation technologies for biogas upgrading. RSC Advances. 2015;5:24399-448.

[15] Moghadassi AR, Rajabi Z, Hosseini SM, Mohammadi M. Fabrication and modification of cellulose acetate based mixed matrix membrane: Gas separation and physical properties. Journal of Industrial and Engineering Chemistry. 2014;20:1050-60.

[16] Sanaeepur H, Kargari A, Nasernejad B. Aminosilane-functionalization of a nanoporous Y-type zeolite for application in a cellulose acetate based mixed matrix membrane for CO2 separation. RSC Advances. 2014;4:63966-76.

[17] Achoundong CSK, Bhuwania N, Burgess SK, Karvan O, Johnson JR, Koros WJ. Silane Modification of Cellulose Acetate Dense Films as Materials for Acid Gas Removal. Macromolecules. 2013;46:5584-94.

[18] Seng KT. Fabrication of amino-functionalized cau-1/ cellulose acetate mixed matrix membrane for $\mathrm{CO}_{2} / \mathrm{N}_{2}$ separation: Universiti Teknologi Petronas; 2016.

[19] Isanejad M, Azizi N, Mohammadi T. Pebax membrane for CO2/CH4 separation: Effects of various solvents on morphology and performance. Journal of Applied Polymer Science. 2017;134:n/a-n/a.

[20] Rafiq S, Man Z, Maulud A, Muhammad N, Maitra S. Effect of varying solvents compositions on morphology and gas permeation properties on membranes blends for $\mathrm{CO} 2$ separation from natural gas. Journal of Membrane Science. 2011;378:444-52.

[21] Askari M, Chung T-S. Natural gas purification and olefin/paraffin separation using thermal cross-linkable co-polyimide/ZIF-8 mixed matrix membranes. Journal of membrane science. 2013;444:173-83.

[22] Jusoh N, Yeong YF, Cheong WL, Lau KK, Shariff AM. Facile fabrication of mixed matrix membranes containing 6FDA-durene polyimide and ZIF-8 nanofillers for CO 2 capture. Journal of Industrial and Engineering Chemistry. 2016;44:164-73.

[23] Jusoh N, Yeong YF, Lau KK, M. Shariff A. Enhanced gas separation performance using mixed matrix membranes containing zeolite $\mathrm{T}$ and 6FDAdurene polyimide. Journal of Membrane Science. 2017;525:175-86. 
[24] Mubashir M, Yeong YF, Lau KK. Ultrasonic-assisted secondary growth of decadodecasil 3 rhombohedral (DD3R) membrane and its process optimization studies in $\mathrm{CO} 2 / \mathrm{CH} 4$ separation using response surface methodology. Journal of Natural Gas Science and Engineering. 2016;30:50-63.

[25] Mohammadi T, Moghadam MT, Saeidi M, Mahdyarfar M. Acid Gas Permeation Behavior Through Poly(Ester Urethane Urea) Membrane. Industrial \& Engineering Chemistry Research. 2008;47:7361-7.

[26] Khan M, Dixit G. Erosive wear response of SiCp reinforced aluminium based metal matrix composite: Effects of test environments. Journal of Mechanical Engineering and Sciences. 2017;14:2401-14.

[27] Sanaeepur H, Kargari A, Nasernejad B, Ebadi Amooghin A, Omidkhah M. A novel $\mathrm{Co} 2+$ exchanged zeolite Y/cellulose acetate mixed matrix membrane for $\mathrm{CO} 2 / \mathrm{N} 2$ separation. Journal of the Taiwan Institute of Chemical Engineers. 2016;60:403-13.

[28] Yusuf M, Selamat M, Sahari J, Daud M, Tahir M, Hamdan H. Fabrication of a flow channel for the production of polymer composite bipolar plates through hot compression molding. Journal of Mechanical Engineering and Sciences. 2017;11:2428-42.

[29] Pak SH, Jeon YW, Shin MS, Koh HC. Preparation of Cellulose Acetate HollowFiber Membranes for $\mathrm{CO} 2 / \mathrm{CH} 4$ Separation. Environmental Engineering Science. 2016;33:17-24. 